\title{
Association of higher Omega-6/Omega-3 fatty acids in the diet with higher prevalence of metabolic syndrome in north India
}

\begin{abstract}
Background: The epidemic of obesity and hypertension over the last two decades, in the middle and high income countries is associated with marked rise in the incidence of metabolic syndrome

Objective: To measure the prevalence of metabolic syndrome (MS) and determine its association with ratio of omega-6/omega-3 fatty acids in the diet.

Design and Methods: Cross-sectional surveys were conducted in 20 urban streets in the city of Moradabad, India. Randomly selected subjects with MS aged 25years and above were evaluated and graded according to omega-6/omega-3 ratio in the diet. Physical examination, sphygmomanometer, questionnaire and blood tests were done.

Results: The overall prevalence of MS was $19.3 \%(\mathrm{n}=387)$ and hypertension $26.6 \%$ $(\mathrm{n}=533)$ without any gender difference. The prevalence of MS, type 2 diabetes, CAD and hypertension showed a trend of higher rate, in relation to omega-6/omega-3 ratio in the diet. Subgroup analysis showed that subjects eating low omega-6/omega-3 ratio $(<5.0)$ diets had significantly lower prevalence of MS, and related components compared to higher ratio diets, among both sexes. Multivariate logistic regression analysis after adjustment of age showed, that hypertriglyceridemia (odds ratio 0.90 in men, 0.76 in women) was strongly $(\mathrm{P}<0.01)$ associated with MS. Hypertension, HDL $-\mathrm{C}$, and central obesity were weakly associated with MS in both sexes. Hypercholesterolemia was weakly associated with MS only in women.

Conclusion: MS has become a public health problem in India. Higher $\mathrm{w}-6 / \mathrm{w}-3$ ratio is a major risk factor of MS and CAD. It is possible that a low w-6/w-3 ratio in the $\operatorname{diet}(<5.0)$ may be protective against MS and related components.
\end{abstract}

Keywords: nutrition, alpha-linolenic acid, food intakes, risk factors, hypertension, coronary disease, diabetes
Volume 6 Issue 6 - 2017

\author{
Ram B Singh,' Jan Fedacko, ${ }^{2}$ Banshi Saboo, ${ }^{3}$ \\ MA Niaz,' Anuj Maheshwari, ${ }^{4}$ Narsingh \\ Verma, ${ }^{5}$ Kshitij Bharadwaj ${ }^{5}$ \\ 'Halberg Hospital and Research Institute, India \\ ${ }^{2}$ Pavol Jozef Safaric University, Slovakia \\ ${ }^{3} \mathrm{Dia}-$ care and Hormone Institute, India \\ ${ }^{4}$ Babu Banarasi Das University, India \\ ${ }^{5} \mathrm{KG}$ Medical University, India
}

Correspondence: Ram B Singh, Halberg Hospital and Research Institute, Moradabad, India, Tel 91 999794102, Email rbs@tsimtsoum.net

Received: October 29, 2017 | Published: December 20, 2017

\section{Introduction}

The epidemic of obesity and hypertension over the last two decades, in the middle and high income countries is associated with marked rise in the incidence of metabolic syndrome (MS), CAD, type 2 diabetes, myocardial infarction and stroke and the total burden of cardiovascular disease (CVD) ${ }^{1-4}$ The metabolic syndrome is associated with constellation of metabolic disturbances, of all the risk factors for CVD. ${ }^{4}$ MS appears to be a major cause of mortality and morbidity due to CVD and diabetes.$^{5-9}$ In the 1920 s, Kylin, a Swedish physician, described MS, as the clustering of hypertension, hyperglycemia, and gout. ${ }^{10}$ However, the concept of the MS has existed for at least 80years. ${ }^{4}$ In 1947, Vague, ${ }^{11}$ drew attention to upper body adiposity (android or male-type obesity) as the obesity phenotype that was commonly associated with metabolic abnormalities characterized with type 2 diabetes and CVD. There is urgent need for strategies to prevent the emerging global epidemic, as this syndrome appears to be a master of disguise since it can present in various ways according to the various components that constitute the syndrome. ${ }^{3-9}$ Reaven, ${ }^{12}$ described the MS as syndrome X, De Fronzo et al., ${ }^{13}$ as the insulin resistance syndrome, and Kaplan, ${ }^{14}$ the deadly quartet. The MS represents a constellation of metabolic abnormalities including glucose intolerance (type 2 diabetes, impaired glucose tolerance, or impaired fasting glycaemia), insulin resistance, central obesity, dyslipidemia, and hypertension, which are well known risk factors for CAD. ${ }^{2,3}$ Epidemiological studies suggest that primary risk factors such as physical inactivity and unbalanced nutritional consumption of excess calories, simple refined carbohydrates with a high glycemic index and load of high saturated fat (SF), trans fatty acids (TFA), and high $\mathrm{w}-6 / \mathrm{w}-3$ ratio and lower monounsaturated fatty acids, in the diet are pro-inflammatory, ${ }^{8-15}$ and contribute to the escalating rates of obesity, MS and mortality due to CVD. ${ }^{1-16}$

In the $5^{\text {th }}$ century $(\mathrm{BCE})$, Confucius, the Chinese philosopher taught his students, "Cereals, the basic, fruits the subsidiary, meat the beneficial and vegetable the supplementary". Therefore, the concept of eating a diet high in animal foods, and preference for meat, possibly wild animals and birds rich in w-3 fatty acids, and whole grain cereals have been shaped over hundreds ofyears among Chinese. While Greek physician Hippocrates (600 BCE) advocated food as medicine, adverse effects of Tamasic foods characteristics of the Western diet, were proposed by Indian ancient physicians; Charak and Sushruta in 600 BCE. Charaka, who was Brahmin, supposed to live in Taxila University in North of India, proposed that "Heart attack is born by the intake of fatty meals, overeating, excess of sleep, lack of exercise and anxiety" (Charaka Sutra, 600BC). Sushruta was 
a surgeon from Vishwamitra family from Varanasi, in East India who was in a position to do surgery and described atherosclerosis as madroga; "Excess intake of fatty foods and lack of exercise causes obesity and narrowing of the channels taking blood to the heart. It is useful to use guggul, triphala and silajit in the treatment". The total fat and saturated fat intake as a percentage of total calories has continuously decreased in Western diets in the last 40years, whereas the omega- 6 fatty acid has increased and the omega- 3 fatty acid decreased, resulting in a large increase in the omega-6/omega -3 ratio from 1:1 during evolution to 20:1 today in the western world. ${ }^{7-9}$ The ratio of omega- 6 and omega-3 fatty acids has markedly increased to $45: 1$ among South Asians, due to marked increase in the intake of sunflower, corn oil and soya bean oils. ${ }^{8,9}$ These dietary changes in the composition of fatty acids are associated with significant increase in the prevalence of obesity, hypertension and metabolic syndrome..$^{17}$ In the present study, we examine the association of $\mathrm{w}-6 / \mathrm{w}-3$ ratio of diet with risk of MS and its other components; hypertension, CAD and dyslipidemia.

\section{Subjects and Methods}

\section{Selection of subjects}

We randomly selected 20 streets from the urban area of the city of Moradabad. From each street; blocks or clusters were randomly selected, and from each block, 40-100 adults, aged 25years and above were randomly selected based on voter's list. When the random number fell to a subject, who was $<25 \mathrm{yrs}$ or not available, it was assigned to next person in the list. We contacted 2422 urban subjects aged $25 \mathrm{yrs}$ and above, of which $220(9.08 \%)$ refused to participate and rest 2002(1016men and 986 women volunteered to be included in the study. Detailed interviews were performed with the help of pretested and validated questionnaire, prepared according to the guidelines of WHO and Indian Council of Medical Research. Dietary assessment was made by 7-day food intake record by questionnaires. Evaluation was by a physician and dietitian administered questionnaire, a physical examination and sphygmomanometer and blood tests. The diagnosis of metabolic syndrome was based on WHO criteria (presence of 3 risk factors or more; hypertension, central obesity, type 2 diabetes or glucose intolerance), and subjects were graded according to $w-6 / w-3$ ratio of fatty acids, in the diet.

\section{Criteria}

Body mass index was calculated and obesity was defined as a body mass index $>30 \mathrm{~kg} / \mathrm{m}^{2}$ and above, overweight when body mass index $>25 \mathrm{~kg} / \mathrm{m}^{2}$ and up to 29.9 . Figures for criteria according to the Indian consensus group for overweight $\left(>23 \mathrm{~kg} / \mathrm{m}^{2}\right)$, were also calculated. Central obesity was considered when waist- hip ratio $>0.90$ in males and $>0.85$ in females were observed, as suggested in previous studies. ${ }^{1,2}$ Diabetes mellitus was diagnosed in presence of fasting blood glucose $>7.7 \mathrm{mmol} / 1(140 \mathrm{mg} / \mathrm{dl})$ and postprandial $2 \mathrm{~h}$ after $75 \mathrm{~g}$ of oral glucose $>11.2 \mathrm{mmol} / 1(>200 \mathrm{mg} / \mathrm{dl})$. Glucose intolerance was diagnosed in presence of fasting glucose between $110-140 \mathrm{mg}$ / $\mathrm{dl}$ and post prandial glucose between 180 to $200 \mathrm{mg} / \mathrm{dl}$. It is difficult to assess tobacco intake, because it is consumed in various forms. Cigarettes, beedies, Indian pipes, raw tobacco and chewing tobacco are all commonly consumed and people use tobacco in more than one form .We therefore categorized users of any form of tobacco as smokers as was done in previous studies. Individuals who admitted to ingesting alcohol more than once a week were categorized as alcohol consuming. Blood pressure was measured in right arm (systolic and diastolic phase $\mathrm{V}$ of Korotkoff) after $5 \mathrm{~min}$ rest in sitting position according to WHO guidelines by a single mercury manometer and by the same physician in all subjects. Hypertension was diagnosed when systolic blood pressure was $140 \mathrm{~mm} \mathrm{Hg}$ or more and diastolic blood pressure $90 \mathrm{mmHg}$ or more. Nutrient intakes were calculated with the help of nutrient composition of Indian foods tables. ${ }^{18}$

\section{The criteria for the diagnosis of CAD were:}

a. History of angina or infarction and previously diagnosed disease;

b. Affirmative response to Rose questionnaire;

c. Electrocardiographic findings, namely Minnesota codes $1-1,4-1,5-9,5-2$ or $9-2$.

Presence of all of these three criteria was taken as confirmation of the diagnosis of CAD. Individual clinical criteria included known CAD, affirmative response to Rose questionnaire and electrocardiographic changes (Q wave change codes 1-1 and 1-2, ST segment depression or elevation codes 4-1, 4-2 and 9-2 and T wave inversions, codes $5-1$ and 5-2. Prevalence rates of these electrocardiographic finding with and without clinical criteria for CAD are also given. A blood sample after an overnight fast was obtained from all subjects. Each participant was asked to drink $75 \mathrm{~g}$ anhydrous glucose in $200 \mathrm{ml}$ of water and a second blood sample was collected after $2 \mathrm{~h}$ for analysis of glucose.

\section{Statistical Analysis}

The prevalence rates are given in percent and numerical variables as mean 1 standard deviation. Significance of association of various risk factors was determined by multivariate logistic regression analysis. Odds ratios and $95 \%$ confidence intervals were calculated by multivariate analysis after adjustment of age and sex using overall prevalence of metabolic syndrome, as the dependent variable. Subjects were classified based on $n-6 / n-3$ ratio in the diet, and the association of various components of metabolic syndrome was demonstrated by Mantel Haenzel Chi square test and Kendal's t test.

\section{Results}

We studied 2002 subjects $25 y$ years and above, from North India. The age and sex distribution of the sample were comparable with the age and sex ratio in the population of Uttar Pradesh. Table 1 shows the fatty acid intakes in the urban population studied compared to a rural population of the same district. ${ }^{19}$ The Consumption of total, saturated fat, polyunsaturated fat and linoleic acid were slightly higher among men compared to women (Table 1). The consumption of alpha-linolenic acid which is a short chain $\mathrm{w}-3$ fatty acid was also higher in men compared to women. The ratio of $w-6 / w-3$ fatty acid showed no significant difference among sexes. Table 2 shows the prevalence of coronary risk factors and metabolic syndrome in our subjects. The prevalence of coronary artery disease, diabetes mellitus, low HDL and tobacco intake were significantly higher among men compared to women. The overall prevalence of metabolic syndrome was $19.3 \%$ without any sex difference. Table 3 shows the prevalence of coronary risk factors, $\mathrm{CAD}, \mathrm{MS}$ and its components in relation to $\mathrm{w}-6 / \mathrm{w}-3$ ratio in the diet. This table shows that there was an overall increase in the prevalence of CAD, type 2 diabetes, hypertension, hypertriglyceridemia $(>150 \mathrm{mg} / \mathrm{dl})$, low HDL, central obesity and metabolic syndrome among subjects consuming high $\mathrm{w}-6 / \mathrm{w}-3$ ratio diet and the trend was significant for both men and women which is 
better depicted in the Figure 1. An increasing ratio of $\mathrm{w}-6 / \mathrm{w}-3$ ratio in the diet was also associated with a rising trend in mean levels of body mass index, waist-hip ratio, blood pressures, Triglycerides, HDL cholesterol and fasting blood glucose and the trends were significant (Table 4). Table 5 shows that there was a significant positive rank correlation between the level of $\mathrm{w}-6 / \mathrm{w}-3$ fat ratio in the diet and components of metabolic syndrome and coronary risk factors; mean age, body weight, body mass index, waist-hip ratio, systolic and diastolic blood pressures, total cholesterol, triglycerides, and fasting blood glucose. Multivariate logistic regression analysis showed that regardless of age, in relation to $\mathrm{w}-6 / \mathrm{w}-3$ ratio in the diet, hypertriglyceridemia, HDL cholesterol, hypertension, central obesity, physical activity, fasting blood glucose were significantly associated with metabolic syndrome among both sexes. Hypercholesterolemia was not associated with MS among men.

Table I Fatty acids consumption in urban subjects.

\begin{tabular}{lll}
\hline Urban & & \\
\hline & $\begin{array}{l}\text { Women } \\
(\mathbf{n}=986)\end{array}$ & $\begin{array}{l}\text { Men } \\
(\mathbf{n}=1016)\end{array}$ \\
\hline Total energy \% k cal/day & 2047 & 2280 \\
Total fatty acids (g/day) & $60.0 \pm 6.8$ & $64.5 \pm 7.6$ \\
Saturated fat (g/day) & $20.5 \pm 4.2$ & $22.0 \pm 5.3$ \\
Monounsaturated (g/day) & $22.5 \pm 4.6$ & $24.5 \pm 5.5$ \\
Polyunsaturated (g/day) & $17.0 \pm 4.1$ & $18.0 \pm 4.4$ \\
Linoleic acid (g/day) & $16.5 \pm 3.8$ & $17.4 \pm 4.0$ \\
Alpha-Linolenic acid (g/day) & 0.510 .11 & $0.64 \pm 0.11$ \\
Omega-6/Omega-3 & $33.0 \pm 5.6$ & $29.0 \pm 5.2$ \\
Polyunsaturated/Saturated fat ratio & $0.82 \pm 0.2$ & $0.82 \geq \pm 0.2$ \\
Prevalence of coronary artery disease (CAD)(n (\%)) & $67(6.8)$ & $119(11.7)$
\end{tabular}

$*=P<0.01$, Total CAD among both sexes. 9.3\%

Table 2 Prevalence of coronary risk factors and metabolic syndrome.

\begin{tabular}{|c|c|c|c|}
\hline Risk factor & Men $(n=1016)$ & Women $(n=986)$ & Total $(n=2002)$ \\
\hline Coronary artery disease & $119(11.7)^{*}$ & $67(6.8)$ & $186(9.3)$ \\
\hline Diabetes mellitus & $81(8.0)^{*}$ & $52(5.3)$ & $133(6.6)$ \\
\hline Hypertension (>140/90) & $285(28.0)$ & $248(25.1)$ & $533(26.6)$ \\
\hline Hypercholesterolemia $(>55.18 \mathrm{~mm})$ hypertriglyceridemia & $313(30.8)$ & $317(32.1)$ & $630(31.4)$ \\
\hline Low high density & $335(33.0)$ & $345(35.0)$ & $680(33.9)$ \\
\hline lipoprotein cholesterol (<1.04mmd) & $275(27.0)^{*}$ & I46(|4.8) & $421(21.0)$ \\
\hline Central obesity ( $>0.90$ men, $>0.85$ women) & $482(47.4)$ & $506(51.3)$ & $1007(50.3)$ \\
\hline Metabolic syndrome & $202(19.8)$ & $185(18.7)$ & $387(19.3)$ \\
\hline Tobacco intake & $202(19.8)^{* *}$ & $18(1.8)$ & $220(10.9)$ \\
\hline Obesity (BMI>25Kg/m²) & $32 \mathrm{I}(3 \mathrm{I} .6)$ & $324(32.8)$ & $645(32.2)$ \\
\hline
\end{tabular}

$*=\mathrm{P}<0.05$ by Chi square test 
Table 3 Prevalence of coronary risk factors in relation to omega-6/ omega-3 ratio of diet.

\begin{tabular}{|c|c|c|c|c|c|c|c|c|}
\hline $\begin{array}{l}\text { W-6/W-3 } \\
\text { Ratio }\end{array}$ & $\begin{array}{l}\text { No. of } \\
\text { Subject }\end{array}$ & CAD & $\begin{array}{l}\text { BP } \\
>I 40 / 90 \mathrm{mmHg}\end{array}$ & Diabetes & $\begin{array}{l}\text { Total triglycerides }>1.69 \\
\mathrm{mmol} / \mathrm{L}\end{array}$ & $\begin{array}{l}\text { HDL } \\
<1.04 \mathrm{mmol} / \mathrm{L}\end{array}$ & $\begin{array}{l}\text { Cen.Obe WHR } \\
>0.90\end{array}$ & $\begin{array}{l}\text { Metabolic } \\
\text { Syndrome }\end{array}$ \\
\hline \multicolumn{9}{|c|}{ Men $(n=|0| 6)$} \\
\hline$<5.0$ & 230 & $8(3.5)$ & $19(8.2)$ & $7(3.0)$ & $2 I(9.1)$ & $14(6.0)$ & $25(10.8)$ & $5(2.3)$ \\
\hline $5.1-10.0$ & 542 & $53(9.7)$ & $170(3 \mid .3)$ & $44(8.1)$ & 188(34.7) & $164(30.2)$ & $277(5 \mathrm{I} . \mathrm{I})$ & $100(18.4)$ \\
\hline$>10.0$ & 244 & $58(23.7)$ & $96(39.4)$ & $30(12.3)$ & $126(5 \mid .6)$ & $97(39.7)$ & $170(69.6)$ & $97(39.7)$ \\
\hline Total & 1016 & $119(11.7)$ & $285(28.0)$ & 81 (7.9) & $335(32.9)$ & $275(25.9)$ & $482(47.4)$ & $202(19.8)$ \\
\hline $\begin{array}{l}\text { Mantel } \\
\text { Haenszel }\end{array}$ & $x^{2}$ & 29.71 & 32.25 & 18.4 & 25.64 & 28.5 & 33.62 & 19.62 \\
\hline PValue & & $<0.001$ & $<0.001$ & $<0.01$ & $<0.001$ & $<0.001$ & $<0.001$ & $<0.01$ \\
\hline \multicolumn{9}{|c|}{ Women(n=986) } \\
\hline$<5.0$ & 233 & $6(2.6)$ & $31(12.8)$ & $5(2.1)$ & $29(12.4)$ & $7(3.0)$ & $28(12.0)$ & $4(1.7)$ \\
\hline $5.1-10.0$ & 515 & $3 I(6.0)$ & $136(26.4)$ & $29(5.6)$ & $178(34.5)$ & $8 I(I 5.7)$ & $275(53.4)$ & $91(17.6)$ \\
\hline$>10.0$ & 238 & $30(12.6)$ & $8 I(34.0)$ & I8(7.5) & $138(58.0)$ & $48(20.1)$ & $203(85.3)$ & $90(37.8)$ \\
\hline Total & 986 & $67(6.8)$ & $248(25.1)$ & $52(5.3)$ & $345(35.0)$ & $\mid 46(\mid 4.8)$ & $506(5 I .3)$ & $185(\mid 8.6)$ \\
\hline $\begin{array}{l}\text { Mantel } \\
\text { Haenszel }\end{array}$ & $x^{2}$ & 30.52 & 28.81 & 19.62 & 33.41 & 22.44 & 29.71 & 17.63 \\
\hline PValue & & $<0.001$ & $<0.001$ & $<0.002$ & $<0.001$ & $<0.002$ & $<0.001$ & $<0.01$ \\
\hline
\end{tabular}

HDL: High Density Lipoprotein Cholesterol;WHR:Waist-Hip Ratio; CAD: Coronary Artery Disease.

Table 4 Risk factor levels in relation to omega-6/omega-3 fat ratio in the diet.

\begin{tabular}{llllll}
\hline w-6/w-3 & B $\quad$ BMI $\left(\mathrm{Kg} / \mathrm{M}^{2}\right)$ WHR & BP $(\mathrm{mmHg})$ & $\begin{array}{l}\text { Triglycerides } \\
(\mathrm{mmol} / \mathrm{L})\end{array}$ & $\begin{array}{l}\text { HDL-C } \\
(\mathrm{mmol} / \mathrm{L})\end{array}$ & $\begin{array}{l}\text { Fasting Blood Glucose } \\
(\mathrm{mmol} / \mathrm{L})\end{array}$ \\
& Systolic Diastolic
\end{tabular}

\begin{tabular}{|c|c|c|c|c|c|c|c|c|}
\hline \multicolumn{9}{|c|}{ Men $(n=1016)$} \\
\hline$>5.0$ & 230 & $20.2(3.2)$ & $0.87(0.10)$ & $119.0(13)$ & $78.5(10)$ & I.27(0.5) & I.I8(0.3) & $4.6(1.0)$ \\
\hline $5.1-10.0$ & 542 & $22.4(4.1)$ & $0.89(0.12)$ & $125.1(16)$ & $84.6(12)$ & $1.68(0.7)$ & I.I7(0.3) & $5.0(1.1)$ \\
\hline$>10.0$ & 244 & $24.5(4.3)$ & $0.92(0.13)$ & $131.6(18)$ & $88.2(14)$ & $1.98(0.8)$ & $1.13(0.2)$ & $5.4(1.2)$ \\
\hline Total & 1016 & $22.4(4.2)$ & $0.89(0.11)$ & $125.3(17)$ & $84 . I(13)$ & $1.66(0.7)$ & $1.16(0.3)$ & $5.0(1.1)$ \\
\hline Kendal's t-test & & 0.047 & 0.98 & 0.105 & 0.091 & 0.035 & 0.031 & 0.037 \\
\hline TValue & & $2.75^{*}$ & $4.8 * *$ & $4.57 * *$ & $4.1 * *$ & $2.43^{*}$ & 1.45 & $2.58^{*}$ \\
\hline \multicolumn{9}{|c|}{ Women $(n=986)$} \\
\hline$>5.0$ & 233 & $20.0(3.1)$ & $0.83(0.09)$ & $21(14)$ & $80.2(11)$ & $1.60(0.5)$ & I.25(0.5) & $4.5(1.0)$ \\
\hline $5.1-10.0$ & 515 & $22.2(3.5)$ & $0.86(0.11)$ & $124(16)$ & $85.5(13)$ & $1.66(0.7)$ & $1.22(0.4)$ & $5.1(I . I)$ \\
\hline$>10.0$ & 238 & $24.7(4.0)$ & $0.89(0.12)$ & $130(17)$ & $89.0(14)$ & I.70(0.8) & I.I7(0.2) & $5.4(1.2)$ \\
\hline Total & 986 & $22.3(3.7)$ & $0.86(0.13)$ & $125(18)$ & $85.1(15)$ & I.66(0.7) & I.22(0.5) & $5.0(1.1)$ \\
\hline Kendal's t-test & & 0.049 & 0.91 & 0.103 & 0.089 & 0.037 & 0.033 & 0.039 \\
\hline TValue & & $2.8 I^{*}$ & $4.6 * *$ & $4.98 * *$ & $3.99 * *$ & $2.65^{*}$ & 1.47 & $2.59 *$ \\
\hline
\end{tabular}

$\mathrm{P}$ value $*=<0.01, * *=<0.001$ 
Table 5 Mean levels of clinical and biochemical risk factors and their correlation with omega-6/omega-3 fat ratio in the diet (Spearman's rank correlation).

\begin{tabular}{|c|c|c|c|c|}
\hline & \multicolumn{2}{|l|}{ Men } & \multicolumn{2}{|l|}{ Women } \\
\hline & Mean & $\mathbf{R}$ & Mean & $\mathbf{R}$ \\
\hline Mean age (years) & $53.5(13)$ & 0.06 & $51.6(11)$ & 0.04 \\
\hline Mean body weight (Kg.) & $64.0(07)$ & $0.08^{*}$ & $52.5(4)$ & $0.09 *$ \\
\hline Body mass index $\left(>25 \mathrm{Kg} . / \mathrm{m}^{2}\right)$ & $25.5(05)$ & $0.08^{*}$ & $22.4(4)$ & $0.09 *$ \\
\hline Waist hip ratio & $0.90(0.2)$ & $0.08^{*}$ & $0.86(0.2)$ & $0.07 *$ \\
\hline Systolic blood pressure $(\mathrm{mmHg})$ & $130(2 \mid)$ & $0.21^{* *}$ & $128(19)$ & $0.19 * *$ \\
\hline Diastolic blood pressure $(\mathrm{mmHg})$ & $88(16)$ & $0.78 * *$ & $84(14)$ & $0.16 * *$ \\
\hline Total cholesterol (mmol/L) & $5.12(1.1)$ & $0.09 *$ & $5.0(1.1)$ & $0.08 *$ \\
\hline Triglycerides (mmol/L) & $1.67(0.06)$ & 0.04 & $1.69(0.07)$ & $0.07 *$ \\
\hline High density lipoprotein Cholesterol(mmol/L) & I.I7(0.04) & -0.05 & $\mathrm{I} .2 \mathrm{I}(0.04)$ & -0.04 \\
\hline Fasting blood glucose (mmol/L) & $5.1(1.2)$ & $0.07 *$ & $5.1(1.1)$ & 0.08 \\
\hline
\end{tabular}

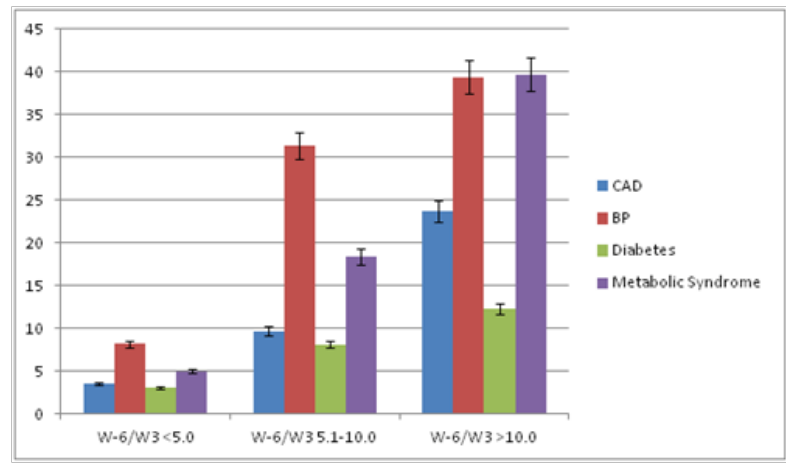

Figure I Prevalence of coronary risk factors in relation to omega-6/ omega-3 ratio of diet in men.

\section{Discussion}

This study shows that various components of MS; hypertension, central obesity, HDL cholesterol, hypertriglyceridemia, fasting blood glucose were significantly associated with MS in relation to $\mathrm{w}-6 / \mathrm{w}-3$ fatty ratio in the diet (Tables 5\&6). People of south Asian origin wherever they are settled have an increased vulnerability to coronary artery disease (CAD) and type 2 diabetes, compared to indigenous populations. ${ }^{1-20}$ The cause of increased susceptibility of south Asians to CAD and diabetes may be due to $\mathrm{MS}^{20,22}$ However, there are no large scale population based studies among South Asians indicating prevalence of MS in South Asia. The prevalence of MS in our study was $19.3 \%(n=387)$ including $19.8 \%$ among men and $18.7 \%$ among women. MS has been observed in many ethnic groups and it is estimated that it is prevalent in approximately one fourth of the adult population of the world..$^{7-21}$ In a multicenter case control study from India, involving 5088 subjects with known type 2 diabetes, the overall prevalence of MS was $77.2 \%$, and the rates were significantly higher among women compared to men, respectively (87.7 vs. $69.3 \%, \mathrm{P}<0.0001) .{ }^{20}$ Important components of MS in this study were, hypertension, followed by hypertriglyceridemia in men and central obesity followed by hypertension in women. In another study from India, among 1806 urban subjects, aged 25-64years, the prevalence of type 2 diabetes mellitus was $6.0 \%$, hypertension $24.0 \%$ and CAD $9.0 \% .{ }^{22}$ Among subjects with diabetes, the prevalence of central obesity was $95.3 \%$, CAD $23.5 \%$ and hypertension $51.6 \%$, which are lower compared to prevalence of these components in Mumbai, West India. These differences in risk factors may be explained by the differences in diet and lifestyle factors in West and North India. ${ }^{23}$

In another study among Indian Immigrants to USA, ${ }^{24}$ the prevalence of MS was $77.0 \%$. These studies indicate an increased susceptibility of Indians to MS, possibly leading to type 2 diabetes and $\mathrm{CAD}$. The prevalence of CAD and diabetes are approximately $3.0 \%$ in rural, $10.0 \%$ in urban and $14.0 \%$ in south India and immigrants to developed countries. ${ }^{19-23}$ The $\mathrm{w}-6 / \mathrm{w}-3$ ratio of the diet is $5 / 1$ to $7 / 1$ in rural, $30 / 1$ to $50 / 1$ in urban subjects, indicating a gradient in the risk with increase in $\mathrm{w}-6 / \mathrm{w}-3$ fatty acids ratio in the diets (Table 1). ${ }^{9-25}$ We observed a high prevalence of CAD, MS and its components in association with increasing ratio of $w-6 / w-3$ fat in the diet and the trends were significant both among men and women (Tables 2-4) (Figure 2). The five city study showed a greater prevalence of CAD in Mumbai (staple oil ground nut), than Kolkata, east India and Moradabad north India who consume mustered oil rich in $\mathrm{w}-3$ fatty acids. ${ }^{1-23}$ The Indian Lifestyle and Heart Study showed, significantly lower prevalence of CAD (11.0 v/s 13.5 and $16.2 \%, \mathrm{P}<0.02)$ compared to subgroups, eating Indian ghee and vegetable ghee + linoleic acid(w-6), respectively, among subjects eating, moderate to heavy fat diets. ${ }^{26}$ The Prevalence of CAD $(3.0 \mathrm{v} / \mathrm{s}$ $7.9,18.2 \%, \mathrm{P}<0.001)$, type 2 diabetes $(2.6 \mathrm{v} / \mathrm{s} 6.9$ and $9.9 \%, \mathrm{P}<0.02)$ and metabolic syndrome $(1.9 \mathrm{v} / \mathrm{s} 18.0$ and $38.8 \%, \mathrm{P}<0.01)$ were significantly lower in the subgroup $(\mathrm{n}=466)$ consuming low $\mathrm{w}-6 / \mathrm{w}-3$ ratio diet $(<5.0)$ compared to subgroups eating higher ratios diets $(5.1 / 1$ to $10.0 / 1, n=1057)$ and $>10.0 / 1(n=482)$. These subgroups also had greater body fat measured by bioelectrical impedance analysis, despite low rates of obesity. ${ }^{27}$ 
Table 6 Age-adjusted Odds Ratio and confidence intervals for association of risk factors with metabolic syndrome in relation to omega-6/omega-3 fat ratio by logistic regression analysis.

\begin{tabular}{|c|c|c|c|c|}
\hline Risk Factors & Odds Ratio & Men $(95 \% \mathrm{Cl})$ & Odds Ratio & Women(95\% Cl) \\
\hline Hypertriglyceridemia & 0.9 & $(0.8 \mathrm{I} \text { to } 0.98)^{* *}$ & 0.76 & $(0.69 \text { to } 0.83)^{* *}$ \\
\hline HDL cholesterol & 0.69 & $(0.62 \text { to } 0.78)^{*}$ & 0.72 & $(0.67 \text { to } 0.79)^{*}$ \\
\hline Hypertension & 0.91 & $(0.82 \text { to } 0.98)^{*}$ & 0.67 & $(0.6 \mathrm{I} \text { to } 0.78)^{*}$ \\
\hline Central obesity & 0.83 & $(0.76 \text { to } 0.92)^{*}$ & 0.86 & $(0.80 \text { to } 0.92)^{*}$ \\
\hline Physical activity & 0.81 & $(0.68 \text { to } 0.97)^{*}$ & 0.46 & $(0.37 \text { to } 0.5 I)^{*}$ \\
\hline Hypercholesterolemia & 0.92 & (0.82 to 1.09$)$ & 0.78 & $(0.7 \mathrm{I} \text { to } 0.87)^{*}$ \\
\hline Fasting blood glucose & 0.84 & $(0.78 \text { to } 0.95)^{* *}$ & 0.81 & $(0.75 \text { to } 0.91)^{*}$ \\
\hline
\end{tabular}

Table 7 Fatty acids consumption in rural and urban subjects.

\begin{tabular}{|c|c|c|c|c|}
\hline \multicolumn{3}{|l|}{ Rural } & \multicolumn{2}{|c|}{ Urban } \\
\hline & $\begin{array}{c}\text { Women } \\
(n=95)\end{array}$ & $\begin{array}{c}\text { Men } \\
(n=984)\end{array}$ & $\begin{array}{l}\text { Women } \\
(n=986)\end{array}$ & $\operatorname{Men}(n=1016)$ \\
\hline Total energy $\% \mathrm{k} \mathrm{cal} /$ day & 2035 & 2267 & 2047 & 2280 \\
\hline Total fatty acids (g/day) & $35.8 \pm 4.8 *$ & $37.6 \pm 5.1 *$ & $60.0 \pm 6.8$ & $64.5 \pm 7.6$ \\
\hline Saturated fat (g/day) & $11.8 \pm 3.4^{*}$ & $12.5 \pm 3.6 *$ & $20.5 \pm 4.2$ & $22.0 \pm 5.3$ \\
\hline Monounsaturated (g/day) & $13.5 \pm 3.5^{*}$ & $14.6 \pm 3.7 *$ & $22.5 \pm 4.6$ & $24.5 \pm 5.5$ \\
\hline Polyunsaturated (g/day) & $10.5 \pm 2.4^{*}$ & $10.5 \pm 2.5^{*}$ & $17.0 \pm 4.1$ & $18.0 \pm 4.4$ \\
\hline Linoleic acid (g/day) & $9.3 \pm 2.5^{*}$ & $9.2 \pm 2.6^{*}$ & $16.5 \pm 3.8$ & $17.4 \pm 4.0$ \\
\hline Alpha-Linolenic acid (g/day) & $1.2 \pm 0.3 *$ & $1.30 \pm .3 *$ & $0.5 \pm 0.11 *$ & $0.6 \pm 0.11 *$ \\
\hline Omega-6/Omega-3 & $7.7 \pm 1.6^{*}$ & $7.0 \pm 1.5^{*}$ & $33.0 \pm 5.6^{*}$ & $29.0 \pm 5.2^{*}$ \\
\hline Polyunsaturated/Polyunsaturated & $0.88 \pm 0.2$ & $0.84 \pm 0.2$ & $0.82 \pm 0.2$ & $0.82 \pm 0.2$ \\
\hline Prevalence of coronary artery disease (CAD)(n (\%)) & $27(2.83)^{*}$ & $40(4.06)^{*}$ & $67(6.8)$ & $119(11.7)$ \\
\hline
\end{tabular}

$*=\mathrm{P}_{7}<0.01$, Total CAD among both sexes. $3.4 \% * 9.3 \%$

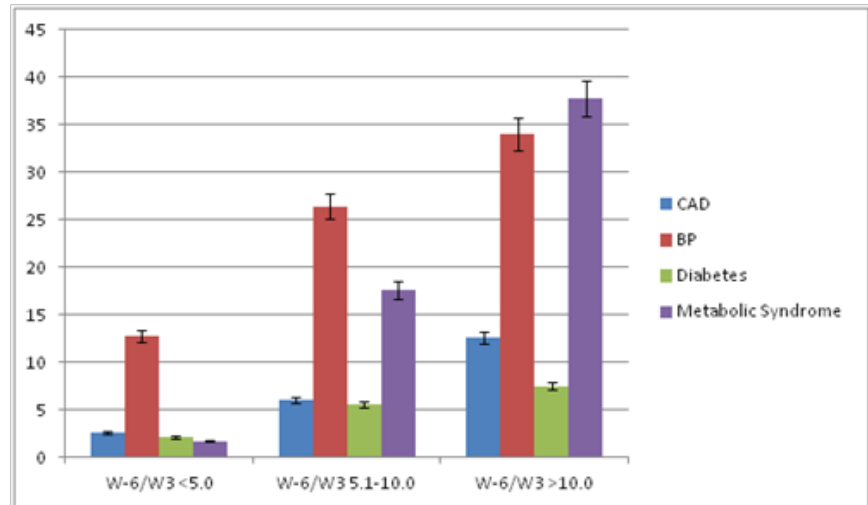

Figure 2 Prevalence of coronary risk factors in relation to omega-6/ omega-3 ratio of diet in women. 
We observed a higher prevalence of CAD, hypertension, diabetes mellitus, hypertriglyceridemia, central obesity and MS and high prevalence of low HDL among subjects consuming high $w-6 / \mathrm{w}-3$ ratio(5.0-10.0 and >10.0) diet compared to subjects taking low $\mathrm{w}-6 / \mathrm{w}-3$ ratio $(<5.0)$ diet among both sexes and the trends were significant (Table 3). The levels of mean systolic and diastolic blood pressures, serum triglycerides, and fasting blood glucose were significantly greater among subjects receiving high $\mathrm{w}-6 / \mathrm{w}-3$ ratio diets, compared to those receiving low $\mathrm{w}-6 / \mathrm{w}-3$ ratio diets in both men and women (Table 4). We also observed a significant positive rank correlation between $\mathrm{w}-6 / \mathrm{w}-3$ ratio in the diet and body mass index, waist/hip ratio, blood pressures and fasting blood glucose (Table 5). There are no population based studies from India regarding association of CAD, MS and diabetes with $\mathrm{w}-6 / \mathrm{w}-3$ ratio in the diet; hence we cannot compare our results with other studies. Deficiencies of EPA and DHA have been observed in subjects of south Asian origin, living in UK. Despite adequate intake of ALA (1.0 to $1.6 \mathrm{mg} /$ day) in the diet, this may be due to decreased delta- 6 , delta- 5 desaturase enzyme activity, responsible for conversion of ALA to EPA and DHA or their increased consumption in the tissues. ${ }^{9}$ There is evidence that green leafy vegetables, whole grains, walnuts, flex seeds and canola oil or mustered oil are rich in alpha-linolenic acid (w-3 fatty acid) and Mediterranean diet or Indo-Mediterranean which is rich in these foods may be protective against cardiovascular disease..$^{28-35}$

In the Lyon diet heart study, ${ }^{33} 605$ patients with post myocardial infarction were randomly assigned to Mediterranean style diet or control diet resembling National Cholesterol Education program step 1 diet. The Mediterranean diet supplied more than $0.6 \%$ energy from alpha-linolenic acid and $<10 \%$ from saturated fatty acid, out of $30 \%$ energy from fats. After a mean follow up of 27 months, the risk of new AMI and episodes of unstable angina were reduced by $70 \%$ in the Mediterranean diet group compared to control group. The IndoMediterranean Diet Heart Study was a randomized, single blind trial, conducted among 1000 patients with high risk of recurrent cardiac events. ${ }^{32}$ Half of the patients $(n=499)$ were administered a diet rich in whole grains, fruits, vegetables, walnuts and mustered or soya bean oil as a source of alpha-linolenic acid (ALA, w-3), and 501 patients were advised to consume prudent diet. After 2years of follow up, the intervention group received two fold greater ALA compared to control group ( 1.8 vs. $0.8 \mathrm{~g} /$ day) resulting into marked decline in the $\mathrm{w}-6 / \mathrm{w}-3$ ratio in the two diets (mean SD 9.1+12 v/s 21+10, $\mathrm{p}<0.001$ ), respectively. Total cardiac events were significantly fewer, in the intervention group, than in the controls $(39 \mathrm{v} / \mathrm{s} 76$ events, $\mathrm{p}<0.001)$. Sudden cardiac deaths were also decreased ( $6 \mathrm{v} / \mathrm{s} 16, \mathrm{p}<0.015)$, as were nonfatal infarction $(21 \mathrm{v} / \mathrm{s} 43, \mathrm{p}<0.001)$. These findings indicate that dietary changes may alter $\mathrm{w}-6 / \mathrm{w}-3$ ratio, which may be associated with large reduction in CAD risk. Further benefit may be observed, if soya bean oil is avoided by using more traditional mustered oil in the Indian diets, as observed in the rural Indian diets (Table 1). In a more recent study ${ }^{36}$ Esposito et al randomized 180 patients with MS to a Mediterranean style diet or a step 1 diet with fat intake $<30.0 \%$. After 2 years, intervention group showed greater weight loss, had lower Creactive proteins and other pro-inflammatory cytokines levels, less insulin resistance, lower total cholesterol and triglycerides and higher HDL-cholesterol levels and had a 50\% decrease in the prevalence of MS. This study confirms that Mediterranean diet provide beneficial effects on inflammation, dyslipidemia as well as decrease insulin resistance and improve endothelial function in patients with MS.

Recent studies indicate that $\mathrm{w}-3$ fatty acids appears to be important in the pathogenesis of acute coronary syndrome and its complications; arrhythmias, heart failure and cardiac events. ${ }^{37-39}$ Further evidence indicate that total fat, saturated fat and trans fat can enhance inflammation and visceral obesity resulting in to MS and treatment with $\mathrm{w}-3$ fatty acids may be beneficial. ${ }^{40-42}$ In a recent study, a total of 117 volunteers completed the 12-week trial. Participants in the 1-, 3-, and 6-portions/d groups reported consuming on average $1.1,3.2$, and 5.6 portions of fruit and vegetables, respectively, and serum concentrations of lutein and $\beta$-cryptoxanthin increased across the groups in a dose-dependent manner. ${ }^{43}$ For each 1 -portion increase in reported fruit and vegetable consumption, there was a $6.2 \%$ improvement in forearm blood flow responses to intraarterial administration of the endothelium-dependent vasodilator acetylcholine $(\mathrm{P}=0.03)$. There was no association between increased fruit and vegetable consumption and vasodilator responses to sodium nitroprusside, an endothelium-independent vasodilator. In an earlier randomized trial in patients with high risk of CVD, two third had MS, supplementation with fruits, vegetables, whole grains and nuts was protective against risk factors; dyslipidemia, hyperglycemia and oxidative stress which are components of MS. ${ }^{44}$ Omega- 3 fatty acids can regulate leptin gene expression and the concentrations of anandamides in the brain, which in turn binds to endogenous cannabinoid receptors and regulate food intake and satiety as well as weight gain. ${ }^{9}$ Deficiency of $\mathrm{w}-3$ fat can increase appetite, resulting into obesity and MS.

CVD, diabetes mellitus, cancer, autoimmune diseases, rheumatoid arthritis, asthma and depression are associated with increased production of thromboxane A2, leucotrienes, interleukins-1 and 6, tumor necrosis factor-alpha and C-reactive proteins. ${ }^{31-35}$ Increased dietary intake of $\mathrm{w}-6$ fatty acids without consideration for $\mathrm{w}-3$ fat is known to enhance all these risk factors as well as atherogenicity of cholesterol and oxidized LDL cholesterol which have adverse pro-inflammatory effects and may result into thrombosis and acute coronary syndrome (ACS), cancer, diabetes mellitus and metabolic syndrome. Omega-3 fatty acids are known to reverse all these biochemical adverse effects hence a low $\mathrm{w}-6 / \mathrm{w}-3$ ration of $1: 1$ has been suggested in the Columbus concept. ${ }^{17}$ Although, most workers working on dietary patterns do not mention the nutrient content of their prudent diet, but one single difference is the $\mathrm{w}-3$ fatty acid, apart from other micronutrients, which is rich in fruits, leafy vegetables, nuts and whole grains. It would be very interesting to know the role of refined starches and sugar, large meals, decreased intake of fruits, vegetables, whole grains and nuts on inflammation and endothelial function and nitric oxide levels as risk predictors of MS and its components. ${ }^{44-51}$ Fruits, vegetables, nuts, whole grains, animal foods rich in $\mathrm{w}-3$ fatty acids are slowly absorbed and may prevent the increase in free fatty acids, and inflammation, which is a characteristic of MS. ${ }^{52}$

There is evidence that omega- 6 and omega -3 fatty acids elicit divergent effects on body fat gain through mechanisms of adipogenesis, browning of adipose tissue, lipid homeostasis, brain-gut-adipose tissue axis, and most importantly systemic inflammation. ${ }^{53-56}$ Prospective studies clearly show an increase in the risk of obesity as the level of omega -6 fatty acids and the omega- $6 /$ omega -3 ratio increase in red blood cell (RBC) membrane phospholipids, whereas high omega-3 RBC membrane phospholipids decrease the risk of obesity. Recent studies in humans show that in addition to absolute amounts of omega -6 and omega -3 fatty acid intake, the omega- 6 / omega -3 ratio plays an important role in increasing the development of obesity via both AA eicosanoids metabolites and hyperactivity of the cannabinoid system, which can be reversed with increased intake of eicosapentaenoic acid (EPA) and docosahexaenoic acid (DHA). 
A balanced omega-6/omega-3 ratio in the diet, in conjunction with reduction in refined carbohydrates and saturated fat are important for health and in the prevention and management of obesity, metabolic syndrome and other chronic diseases. ${ }^{57-59}$

\section{Conclusion}

This study reveal that high $\mathrm{w}-6 / \mathrm{w}-3$ ratio in the diet appears to be a risk factor of MS and its components; hypertension, hypertriglyceridemia, hyperglycemia, low HDL and central obesity. Our findings validate that increased intake of $w-3$ rich foods and lower intake of $\mathrm{w}-6$ fatty acids with low $\mathrm{w}-6 / \mathrm{w}-3$ fatty acid ratio in the diet may be protective against MS. Further studies are necessary to confirm our findings.

\section{Acknowledgement}

We would like to thank International College of Nutrition and Sandoz Foundation of Gerontologic Research for providing financial support to conduct this study.

\section{Conflict of Interest}

None.

\section{Funding}

None.

\section{References}

1. Singh RB, Pella D, Mechirova V, et al. Prevalence of obesity, physical inactivity and undernutrition, a triple burden of diseases, during transition in a developing economy: The Five City Study Group. Acta Cardiol. 2007;62(2):119-127.

2. Kastorini CM, Milionis HJ, Esposito K, et al. The effect of Mediterranean diet on metabolic syndrome and its components. J Am Coll Cardiol. 2011;57(11):1299-1313.

3. Singh RB, Fedacko J, Pella D, et al. Prevalence and risk factors of pre-hypertension and hypertension in five Indian cities. Acta Cardiol. 2011;66(1):29-37.

4. Sofi F, Abbate R, Gensini GF, et al. Accruing evidence about benefits of adherence to Mediterranean diet on health: an updated systematic review with meta-analysis. Am J Clin Nutr. 2010;92(5):1189-1196.

5. Cameron AJ, Shaw JE, Zimmet PZ . The metabolic syndrome: prevalence in worldwide populations. Endocrinol Metab Clin North Am. 2004;33(2):351-375.

6. Mortality and burden of disease estimates for WHO Member States in 2008. Geneva: World Health Organization. 2010.

7. Simopoulos AP. An Increase in the Omega-6/Omega-3 Fatty acid ratio increases the risk for obesity. Nutrients. 2016;8(3):128.

8. Fedacko J, Vargova V, Singh RB, et al. Association of high w-6/w-3 fatty acid ratio diet with causes of death due to non-communicable diseases among urban decedents in North India. The Open Nutraceuticals Journal. 2012;5:113-123.

9. Shastun S, Chauhan AK, Singh RB. Can functional food security decrease the epidemic of obesity and metabolic syndrome? A viewpoint. World Heart. 2016;8:73-80.

10. Fedacko J, Singh RB, Singh S, et al. Association of increased mortality with underweight, overweight and obesity among urban decedents in North India, dying due to various causes. World Heart J. 2008;2(1):341347.
11. Eberly LE, Prineas R, Cohen JD, et al. Metabolic syndrome: risk factor distribution and 18 year mortality in the multiple risk factor intervention trial. Diabetes Care. 2006;29(1):123-130.

12. He Y, Jiank B, Wang Jie, et al. Prevalence of the metabolic syndrome and its relation to cardiovascular disease in an elderly Chinese population. $J$ Am Coll Cardiol. 2006;47(8):1588-1594.

13. Singh RB, Pella D, De Meester F, et al. Fatty acids in the causation and therapy of metabolic syndrome. Wild Type Food in Health Promotion and Disease Prevention, The Humana Press Inc, USA. 2008;263-284.

14. Kylin E. Studies hypertension-hyperglycemia-hyperuricemia syndrome. Zentralbl Inn Med. 1923;44:105-127.

15. Vague J. Sexual differentiation : a determinant factor on the forms of obesity. Obes Res. 1947;4(2):201-203.

16. Reaven GM. Banting lecture 1988. Role of insulin resistance in human disease. Diabetes. 1988;37(12):1595-1607.

17. De Fronzo RA, Ferrannini E. Insulin resistance: A multifaceted syndrome responsible for NIDDM, obesity, hypertension, dyslipidemia, and atherosclerotic cardiovascular disease. Diabetes Care. 1991;14(3):173194.

18. Kaplan NM. The deadly quartet: Upper-body obesity, glucose intolerance, hypertriglyceridemia, and hypertension. Arch Intern Med. $1989 ; 149(7): 1514-1520$

19. Lemieux I, Pascot A, Couillard C, et al. Hypertriglyceridemic waist: a marker of the atherogenic metabolic triad (hyperinsulinemia; hyperapolipoprotein B; small, dense LDL) in men?, Circulation. 2000;102(2):179-184

20. Singh RB, Rastogi SS, Rastogi V, et al. Blood pressure trends, plasma insulin levels and risk factors, in rural and urban elderly populations of north India. Coron Artery Dis. 1997;8(7): 463-468.

21. De Meester F. Wild-type land based foods in health promotion and disease prevention: the LDL-CC: HDL-CC model. Wild Type Foods in Health Promotion and Disease Prevention, Humana Press, USA. 2008;3-20.

22. Narsingrao BS, Deosthale YG, Pant KC. Nutritive Value of Indian Foods. Indian Council of Medical Research, India. 1989;1-14.

23. Singh RB, Sharma JP, Rastogi V, et al. Prevalence of coronary artery diseases and coronary risk factors in rural and urban populations of north India. Eur Heart J. 1997;18(11): 1728-1735.

24. Surana SP, Shah DB, Gala K, et al. Prevalence of metabolic syndrome in an urban Indian diabetic population using the NCEP ATP III guidelines. $J$ Assoc Physicians India. 2008;56: 865-868.

25. Dunstan DW, Zimmet PJ, Welborn TA, et al. The rising prevalence of diabetes and impaired glucose intolerance: The Australian obesity, diabetes and lifestyle study. Diabetes Care. 2002;25(5):829-834.

26. Singh RB, Bazaz S, Niaz MA, et al. Prevalence of type 2 diabetes mellitus and risk of hypertention and coronary artery disease in rural and urban population with low rates of obesity. Int J Cardiol. 1998;66(1):65-72.

27. Singh RB, Beegom R, Verma SP, et al. Association of dietary factors and other coronary risk factors with social class in women in five Indian cities. Asia Pac J Clin Nutr. 2000;9(4):298-302.

28. Foucan L, Deloumeaux J, Donnet JP, et al. Metabolic syndrome components in Indian migrants with type 2 diabetes. A matched comparative study. Diabetes Metab. 2006;32(4):337-342.

29. Pella D, Dubnov G, Singh RB, et al. Effects of an Indo-Mediterranean diet on the omega-6/omega-3 ratio in patients at high risk of coronary artery disease: The Indian paradox. World Rev Nutr Diet. 2003;92:74-80.

30. Singh RB, Niaz MA, Ghosh S, et al. Association of trans fatty acids(vegetable ghee), and clarified butter(Indian ghee) intake with higher 
risk of coronary artery disease, in rural and urban populations with low fat consumption. Int J Cardiol. 1996;56(3):289-298.

31. Singh RB, Niaz MA, Beegom R, et al. Body fat percent by bioelectrical impedence analysis and risk of coronary artery disease among urban men, with low rates of obesity: the Indian paradox. $J$ Am Coll Nutr. 1999;18(3):268-273.

32. Singh RB, Otsuka K, Chiang CE, et al. Nutritional predictors and modulators of metabolic syndrome. J Nutr Environ Med. 2004;14:3-16.

33. Katcher HI, Legro RS, Kunselman AR, et al. The effects of whole grainenriched hypocaloric diet on cardiovascular disease risk factors in men and women with metabolic syndrome. Am J Clin Nutr. 2008;87(1):79-90.

34. Fung TT, Rexrode KM, Mantzoros CS, et al. Mediterranean diet and incidence of and mortality from coronary heart disease and stroke in women. Circulation. 2009;119(8):1093-1100.

35. Simopoulos AP. Importance of the ratio of omega-6/omega-3 essential fatty acids: evolutionary aspects. World Rev Nutr Diet. 2003;92:1-22.

36. Singh RB, Dubnov G, Niaz MA, et al. Effect of an Indo-Mediterranean diet on progression of coronary disease in high risk patients: a randomized single blind trial. Lancet. 2002;360(9344):1455-1461.

37. De Lorgeril M, Renaud S, Mamelle N, et al. Mediterranean alpha-linolenic acid-rich diet in secondary prevention of coronary heart disease. Lancet. 1994;343(8911):1454-1459.

38. Renaud S, De Lorgeril M, Delaye J, et al. Cretan Mediterranean diet for prevention of coronary heart disease. Am J Clin Nutr. 1995;61(6 Suppl):1360S-1367S.

39. Mechirova V, Singh RB, De Meester F, et al. Can wild whole seeds protect against cardiovascular disease. World heart J. 2008;1:137-138.

40. Esposito K, Marfella R, Clotola M, et al. Effect of Mediterranean style diet on endothelial dysfunction and markers of vascular inflammation in the metabolic syndrome: A randomised trial. JAMA. 2004;292(12):14401446 .

41. Smith PJ, Blumenthal JA, Babyak MA, et al. Association between n-3 fatty acid consumption and ventricular ectopy after myocardial infarction. Am J Clin Nutr. 2009;89(5):1315-1320.

42. Campos H, Baylin A, Willett WC. Alpha-Linolenic acid and risk of nonfatal acute myocardial infarction.Circulation. 2008;118(4):339-345.

43. Harris WS, Reid KJ, Sands SA, et al. Blood omega-3 and trans fatty acids in middle aged acute coronary syndrome patients. Am J Cardiol. 2007;99(2):154-158.

44. Micallef MA, Munro IA, Garg ML. An inverse relationship between plasma n-3 fatty acids and C-reactive protein in healthy individuals. Eur J Clin Nutr. 2009;63(9):1154-1156.

45. Storlien LH, Jenkins AB, Chisholm DJ, et al. Influence of dietary fat composition on development of insulin resistance in rats . Relationship to muscle triglyceride and omega -3 fatty acids in muscle phospholipid. Diabetes. 1991;40(2):280-289.

46. Axen KV, Dikeakos A, Sclafani A. High dietary fat promotes syndrome $\mathrm{x}$ in nonobese rats. J Nutr. 2003;133(7):2244-2249.

47. Mc Call DO, Mc Gartland CP, Mc Kinley MC, et al. Dietary intake of fruits and vegetables improves microvascular Function in Hypertensive Subjects in a Dose-Dependent Manner. Circulation. 2009;119(16):21532160 .

48. Singh RB, Rastogi SS, Niaz MA, et al. Effects of fat modified and fruits vegetable enriched diets on blood lipids in the Indian diet heart study. Am J Cardiol. 1992;70(9):869-874.

49. Hristova K, Pella D, Singh RB, et al. Sofia declaration for prevention of cardiovascular diseases and type 2 diabetes mellitus: a scientific statement of the international college of cardiology and international college of nutrition. World Heart J. 2014;6(2):89-106.

50. Shehab A, Elkilany G, Singh RB, et al. Coronary risk factors in Southwest Asia. Editorial, World Heart J. 2015;7(1):21-29.

51. Chauhan AK, Singh RB, Ozimek L, et al. Viewpoint: Saturated fatty acid and sugar; how much is too much for health? A scientific statement of the International College of Nutrition. World Heart J. 2016;8(1):71-78.

52. WHO Expert Consultation Appropriate body-mass index for Asian populations and its implications for policy and intervention strategies. Lancet. 2004;363(9403):157-163.

53. Huang CW, Chien YS, Chen YJ, et al. Role of $n-3$ polyunsaturated aatty acids in ameliorating the obesity-induced metabolic syndrome in animal models and humans. Int J Mol Sci. 2016;17(10):1689.

54. Yu L, Wang S, Ding L, et al. Lower $\omega-6 / \omega-3$ polyunsaturated Fatty Acid Ratios Decrease Fat Deposition by Inhibiting Fat Synthesis in Gosling. Asian-Australas J Anim Sci. 2016;29(10):1443-1450.

55. Jumbe T, Comstock SS, Hahn SL, et al. Whole Blood Levels of the $\mathrm{n}-55$ Essential Fatty Acid Linoleic Acid Are Inversely Associated with Stunting in 2-to-6 Year Old Tanzanian Children: A Cross-Sectional Study. PLoS One. 2016;11(5): 0154715.

56. Molfino A, Amabile MI, Monti M, et al. The Role of Docosahexaenoic Acid (DHA) in the Control of Obesity and Metabolic Derangements in Breast Cancer. Int J Mol Sci. 2016;17(4):505.

57. Bantle JP. Dietary fructose and metabolic syndrome and diabetes. J Nutr. 2009;139(6):1263S-1268S.

58. Johnson RK, Appel LJ, Brands M, et al. Dietary sugars intake and cardiovascular health. A scientific statement from the American Heart Association. Circulation. 2009;120(11):1011-1020.

59. Esposito K, Giugiliano D. Diet and inflammation: a link to metabolic and cardiovascular diseases. Eur Heart J. 2006;27(1):15-20. 